\title{
Factors associated with marketable milk production recovery after treatment of naturally occurring acute coliform mastitis
}

\author{
Yasunori SHINOZUKA ${ }^{1)}$, Sohei KANEKO ${ }^{2)}$, Tomoyasu KUROSE ${ }^{3)}$, Aiko WATANABE ${ }^{1)}$, Kana KURUHARA ${ }^{1)}$ and \\ Kazuhiro KAWAI ${ }^{1) *}$
}

${ }^{1)}$ School of Veterinary Medicine, Azabu University, Sagamihara, Kanagawa 252-5201, Japan

${ }^{2)}$ Fuchu Veterinary Clinical Center, 396-1 Fukae, Joge, Fuchu, Hiroshima 729-3421, Japan

${ }^{3)}$ Kitahiroshima Veterinary Clinical Center (Hatsukaichi branch), 10-14, Honmachi, Hatsukaichi 738-0015, Japan

(Received 1 December 2015/Accepted 27 January 2016/Published online in J-STAGE 9 February 2016)

ABSTRACT. Milk production loss after recovery from acute coliform mastitis causes major economic losses for dairy industries. Declines in milk production and composition are caused by multiple factors, including cow factors, microorganisms and treatments, but the influence of each factor has not been determined. To investigate risk factors for milk loss after treatment for acute coliform mastitis, multiple logistic regression analyses were conducted in 53 clinical cases. Systemic administration of fluoroquinolone was significantly associated with recovery of marketable milk production. The time to slaughter was significantly shorter in cows with complete loss of quarter milk production than in cows that produced marketable milk. In this study, we identified factors associated with increased risk of milk production loss. KEY WORDS: acute coliform mastitis, fluoroquinolone, milk loss, risk factor

doi: 10.1292/jvms.15-0689; J. Vet. Med. Sci. 78(5): 917-920, 2016

Acute coliform mastitis, caused by gram-negative bacteria, such as Escherichia coli (many serotypes), Klebsiella species (numerous capsular types) and Enterobacter aerogenes, is one of the major sources of economic loss in dairy farms, because its effects tend to be fatal [7]. The milk yield of infected cows decreases sharply; occasionally, complete loss of milk production in a mammary quarter occurs. The best outcome of mastitis therapy is a positive effect on the amount of marketable milk harvested and long-term survival of the cow. Therefore, an effective treatment that minimizes the adverse impact of coliform mastitis on milk yield is urgently required. A previous study reported that the efficacy of enrofloxacin, which is an antibiotic authorized for treatment of mastitis in Japan, did not improve the return of quarter milk production in cases of naturally occurring $E$. coli mastitis [13]. On the other hand, using enrofloxacin to treat cows with experimentally induced $E$. coli mastitis after parturition reduced the severity of the disease, especially the decline in milk production and the changes in milk composition [6]. Pathogens causing the most significant losses in older cows have been reported [3]; milk loss varied according to pathogen (including E. coli and Klebsiella species) and case number [4].

Despite many studies of the relationship between acute coliform mastitis and subsequent milk loss, the best treatment option to prevent mammary tissue damage caused by

\footnotetext{
*Correspondence to: Kawai, K., School of Veterinary Medicine, Azabu University, Sagamihara, Kanagawa 252-5201, Japan. e-mail: kawai@azabu-u.ac.jp

(C2016 The Japanese Society of Veterinary Science

This is an open-access article distributed under the terms of the Creative Commons Attribution Non-Commercial No Derivatives (by-nc-nd) License $<$ http://creativecommons.org/licenses/by-nc-nd/4.0/>.
}

acute coliform mastitis is uncertain, because the mechanisms responsible for mammary epithelial and tissue damage during mastitis are still unknown. The aim of this study was to identify possible risk factors for subsequent milk loss after recovery from acute coliform mastitis using logistic regression analysis.

Fifty-three Holstein-Friesian cows from 31 farms in Hiroshima-pref. were enrolled in this study. All cows included had only 1 quarter affected and were diagnosed with acute coliform mastitis that was classified as moderate at the first examination and cured 14 days later. Both diagnoses were established by clinical veterinarians. The severity of disease was classified at the first examination by the Systemic Severity Score, as previously reported [15]. None of the cows had a clinical history of chronic mastitis or other complications. Milk samples for bacterial isolation were collected from the diagnosed cows at the time of the clinical examination, before antibiotic treatment began. All cows were treated with supportive fluid therapy. The experiment was done based on the ethical code for animal welfare of the Azabu University. Survey target data including cow age, days in milk, cattle traceability system number, systemic and local signs, and initial treatment were collected from the Total Clinical Recording System at the Veterinary Clinical Center of NOSAI Hiroshima. Initial treatment data included body temperature, systemic nonsteroidal anti-inflammatory drug (NSAID) administration, systemic and local antibiotic administration, systemic and local steroid administration, and mammary irrigation regimen after frequent milking out. Systemic and local antibiotics were categorized into three groups: none, fluoroquinolones (FQs) and others. Thirty days after clinical cure, we interviewed owner to obtain information about milk yield recovery and marketing of milk. In addition, survival days after initial treatment were calculated with the Japanese 
Table 1. Bivariate analyses of risk factors for quarter milk loss after acute coliform mastitis

\begin{tabular}{|c|c|c|c|c|}
\hline \multirow{3}{*}{ Variables } & \multirow{3}{*}{ Category } & \multicolumn{2}{|c|}{ Outcome } & \multirow{3}{*}{$P$ value } \\
\hline & & Complete loss of quarter & Marketable milk & \\
\hline & & $(n=21)$ & $(n=32)$ & \\
\hline \multicolumn{5}{|l|}{ Continuous variables ${ }^{\mathrm{a})}$} \\
\hline Age (days) & & $1,746 \pm 536$ & $1,856 \pm 612$ & 0.611 \\
\hline Days in milk (days) & & $143 \pm 135$ & $106 \pm 100$ & 0.398 \\
\hline Body temperature $\left({ }^{\circ} \mathrm{C}\right)$ & & $40.2 \pm 0.7$ & $40.1 \pm 1.2$ & 0.978 \\
\hline \multicolumn{5}{|l|}{ Categorical variables } \\
\hline \multirow[t]{2}{*}{ Bacteria } & Klebsiella spp. & 6 & 12 & 0.565 \\
\hline & E. coli & 15 & 20 & \\
\hline \multirow[t]{3}{*}{ Systemic antibiotic } & None & 6 & 6 & \\
\hline & FQ & 2 & 14 & 0.013 \\
\hline & Others & 13 & 12 & 0.099 \\
\hline \multirow[t]{3}{*}{ Local antibiotic } & None & 5 & 13 & \\
\hline & FQ & 6 & 13 & 0.400 \\
\hline & Others & 9 & 6 & 0.070 \\
\hline \multirow[t]{2}{*}{ Systemic NSAID } & No & 5 & 10 & 0.756 \\
\hline & Yes & 16 & 22 & \\
\hline \multirow[t]{2}{*}{ Systemic steroid } & No & 16 & 23 & 1.000 \\
\hline & Yes & 5 & 9 & \\
\hline \multirow[t]{2}{*}{ Local steroid } & No & 6 & 10 & 1.000 \\
\hline & Yes & 15 & 21 & \\
\hline \multirow[t]{2}{*}{ Mammary irrigation regimen } & No & 6 & 4 & 0.169 \\
\hline & Yes & 15 & 28 & \\
\hline
\end{tabular}

a) The data represent the mean \pm standard deviation. FQ, fluoroquinolone; NSAID, nonsteroidal antiinflammatory drug.

cattle traceability system.

Bacteria in milk samples were isolated by incubation in the CHROMagar ${ }^{\mathrm{TM}}$ Orientation (Kanto Chemical Co., Inc., Tokyo, Japan) under aerobic conditions at $37^{\circ} \mathrm{C}$ for $24 \mathrm{hr}$. Isolated bacteria were identified by criteria detailed in a previous report [11], and growth was confirmed by additional laboratory tests in accordance with the routines at the laboratory [12]. E. coli or Klebsiella pneumoniae was isolated from the 53 quarters of 53 cows enrolled in this study. Each bacterial isolate was susceptible to an antibiotic that was used to treat the cow.

The main outcome measure was milk production in a treated quarter (marketable milk or complete loss). The differences between outcome and continuous/categorical variables were examined first. A logistic regression model was used to analyze the strength of the associations.

Continuous variables (age, days in milk and body temperature) in both groups were examined using the MannWhitney U test. Categorical variables were pathogen (E. coli or K. pneumoniae), systemic administration of NSAID (yes or no), systemic administration of steroid (yes or no), intramammary administration of steroid (yes or no), systemic administration of antibiotics (none, FQ or others), intramammary administration of antibiotics (none, FQ or others) and treatment with mammary irrigation (yes or no). Categorical variables were assessed by Fisher's exact test and then chosen based on their statistical significance $(P<0.20)$. However, all variables associated with antibiotic therapy were chosen without regard to statistical significance, because of their clinical importance. A direct multivariate logistic regression model was then used to assess the associations among the outcome variables and the suspected factors. No significant correlations or interactions were found between any of the variables studied. Adequacy of the multivariate model was estimated by the Hosmer-Lemeshow test. The Kaplan-Meier method with the log-rank test was used to compare survival (time to slaughter) curves between outcomes. All statistical analyses were performed with EZR (Saitama Medical Center, Jichi Medical University, Saitama, Japan), which is a graphical user interface for R (the R foundation for Statistical Computing, Vienna, Austria). This is a modified version of $\mathrm{R}$ commander that enables the application of statistical functions frequently used in biostatistics. [9].

After analyses of continuous and categorical variables (Table 1), three categorical variables (systemic administration of antibiotics, intramammary administration of antibiotics and mammary irrigation regimen) that were significant at $P$-value $<0.20$ were selected for multivariate logistic regression analysis. Systemic administration of FQ was the only independent predictor associated with outcome, compared with the group that received no antibiotic (odds ratio, 21.7; 95\% confidence interval, 1.48-317.00) (Table 2). There were no significant differences in any other variables. Survival curves were significantly different between outcomes (harvesting of marketable milk or complete loss of milk in a quarter) ( $P=0.046$, time-to-event analysis, log-rank test; 
Table 2. Adjusted odds ratios associated with marketed milk production recovery after recovery from acute coliform mastitis

\begin{tabular}{|c|c|c|c|c|c|}
\hline \multirow{2}{*}{ Variables } & \multirow{2}{*}{ Category } & \multirow{2}{*}{$\begin{array}{l}\text { Adjusted } \\
\text { odds ratio }\end{array}$} & \multicolumn{2}{|c|}{$95 \%$ confidence interval } & \multirow{2}{*}{$P$ value } \\
\hline & & & Lower & Upper & \\
\hline \multirow[t]{3}{*}{ Systemic antibiotic } & None & Reference & & & \\
\hline & FQ & 21.7 & 1.48 & 317 & $0.0247^{\mathrm{a})}$ \\
\hline & Others & 1.74 & 0.33 & 9.24 & 0.517 \\
\hline \multirow[t]{3}{*}{ Local antibiotic } & None & Reference & & & \\
\hline & FQ & 0.18 & 0.02 & 1.55 & 0.119 \\
\hline & Others & 0.35 & 0.06 & 1.88 & 0.219 \\
\hline \multirow[t]{2}{*}{ MIR } & No & Reference & & & \\
\hline & Yes & 1.49 & 0.29 & 7.65 & 0.635 \\
\hline
\end{tabular}

a) $P<0.05$ was considered statistically significant. FQ, fluoroquinolone; MIR, mammary irrigation regimen.

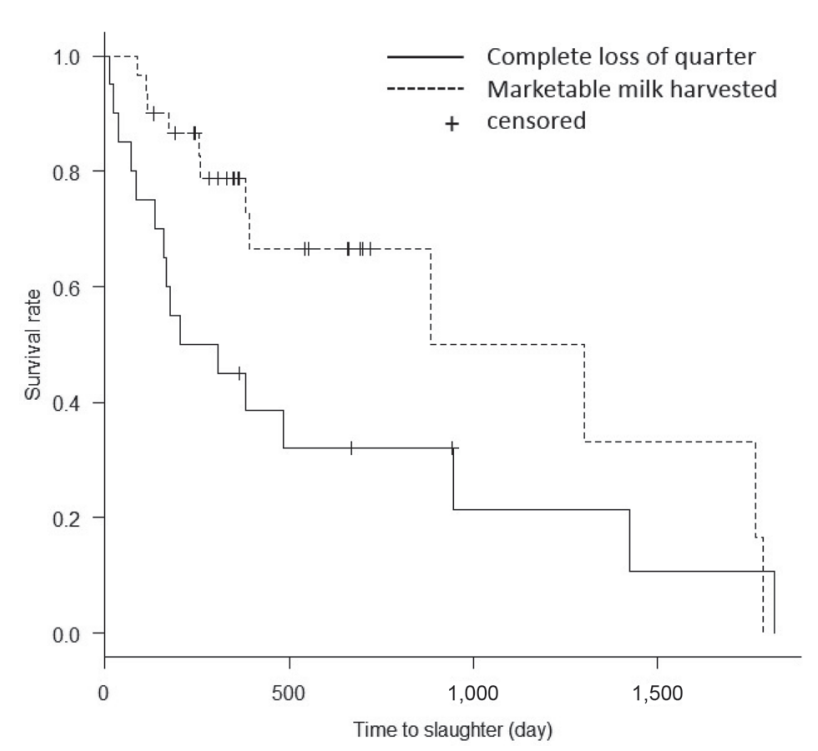

Fig. 1. Kaplan-Meier survival curves for milk production after acute mastitis. The survival rate of cows producing marketable milk was significantly greater than that of cows with complete milk loss in a quarter $(P=0.046$, log-rank test $)$.

Fig. 1). The time to slaughter was significantly shorter in cows with complete loss of quarter milk production than in those that produced marketable milk.

Our results indicate that systemic FQ administration is a significant factor in milk production after mastitis. Decreased milk production is caused by mammary tissue damage, which reduces the number and activity of mammary epithelial cells. In acute coliform mastitis, mammary tissue damage is caused directly by the microorganism and indirectly by lipopolysaccharide (LPS) [16], which is a part of the outer cell wall of bacteria. FQs are lipid-soluble compounds that disperse well throughout the body and to the mammary gland [10]. Direct damage to mammary tissue may be prevented by rapid kill and reduction of bacteria counts in milk. According to in vitro [1] and in vivo [5] studies, LPS does not cause mammary tissue damage directly. However, it is possible that LPS induces apoptosis or necrosis in mammary epithelial cells indirectly through induction of proteases or proinflammatory cytokines [16]. FQs are bactericidal against gram-negative bacteria and cause less release of LPS than do drugs that target the cell wall [14]; therefore, they may prevent mammary tissue damage from antibiotic-induced LPS. In this study, however, intramammary treatment was not a significant factor in milk loss. Although a previous study showed no significant reduction of the antimicrobial activity of enrofloxacin in milk [2], our results indicate that extralabel intramammary infusion of FQ experimentally conducted under the supervision of a veterinarian is not a significant factor in milk production recovery after acute coliform mastitis. It is possible that the action of FQs was hindered by divalent metal ions, such as calcium, and that diffusion of drug to the inflamed quarter was insufficient. Because the concentration of enrofloxacin in milk is considerably higher than in plasma [8], systemic administration of FQs could be sufficient to control bacteria in cases of acute coliform mastitis. Unlike previous reports $[3,4]$, there were no differences in age, pathogen and subsequent milk loss. This may be the stronger influence of treatment relatively. Loss of quarter milk production may shorten the productive life of cows and cause economic damage to dairy farmers. To prevent economic losses in the dairy industry, it is important to maintain long-term survival through continued milk production after recovery from acute coliform mastitis. In this study, logistic regression analysis was used to determine risk factors for milk loss after recovery from acute coliform mastitis based on previous reports $[3,4,6,13]$. Though statistical association does not guarantee causation, our results can be taken into account in future studies.

In conclusion, systemic administration of FQ as the initial treatment of acute coliform mastitis classified as moderate was significantly associated with the prevention of subsequent milk loss. Though acute mastitis was caused by various agents, in the case of coliform mastitis, this knowledge will allow practitioners to provide appropriate treatment, and infected cows may be able to live longer by maintaining productivity. Studies of local treatments other than antibiotics to reduce tissue damage in acute coliform mastitis are required. 
ACKNOWLEDGMENT. We thank the staff of the NOSAI Hiroshima mastitis research group for their help and participation in sample and data collection.

\section{REFERENCES}

1. Capuco, A. V., Paape, M. J., Smith, J. J. and Loeffler, D. A. 1985. In vitro effect of bacterial toxins on lactating bovine mammary tissue. J. Dairy Sci. 68 Suppl. 1: 206.

2. Fang, W. and Pyörälä, S. 1996. Mastitis-causing Escherichia coli: serum sensitivity and susceptibility to selected antibacterials in milk. J. Dairy Sci. 79: 76-82. [Medline] [CrossRef]

3. Gröhn, Y. T., Wilson, D. J., González, R. N., Hertl, J. A., Schulte, H., Bennett, G. and Schukken, Y. H. 2004. Effect of pathogenspecific clinical mastitis on milk yield in dairy cows. J. Dairy Sci. 87: 3358-3374. [Medline] [CrossRef]

4. Hertl, J. A., Schukken, Y. H., Welcome, F. L., Tauer, L. W. and Gröhn, Y. T. 2014. Pathogen-specific effects on milk yield in repeated clinical mastitis episodes in Holstein dairy cows. J. Dairy Sci. 97: 1465-1480. [Medline] [CrossRef]

5. Hill, A. W. 1991. Somatic cells-Friends or foes? pp. 217-232. In: New Insights into the Pathogenesis of Mastitis. (Burvenich, C. Vandeputte-Van, M.G. and Hill, A.W. eds.) Flemish Vet. J., Merelbeke.

6. Hoeben, B. D., Monfardini, E., Burvenich, C. and Hamann, J. 2000. Treatment of acute Escherichia coli mastitis in cows with enrofloxacin: effect on clinical signs and chemiluminescence of circulating neutrophils. J. Dairy Res. 67: 485-502. [Medline] [CrossRef]

7. Hogan, J. and Larry Smith, K. 2003. Coliform mastitis. Vet. Res. 34: 507-519. [Medline] [CrossRef]

8. Kaartinen, L., Salonen, M., Alli, L. and Pyörälä, S. 1995.
Pharmacokinetics of enrofloxacin after single intravenous, intramuscular and subcutaneous injections in lactating cows. J. Vet. Pharmacol. Ther. 18: 357-362. [Medline] [CrossRef]

9. Kanda, Y. 2013. Investigation of the freely available easy-to-use software 'EZR' for medical statistics. Bone Marrow Transplant. 48: 452-458. [Medline] [CrossRef]

10. Malbe, M., Salonen, M., Fang, W., Oöpik, T., Jalakas, M., Klaassen, M. and Sandholm, M. 1996. Disposition of enrofloxacin (Baytril) into the udder after intravenous and intra-arterial injections into dairy cows. Zentralbl. Veterinarmed. A 43: 377-386. [Medline] [CrossRef]

11. Merlino, J., Siarakas, S., Robertson, G. J., Funnell, G. R., Gottlieb, T. and Bradbury, R. 1996. Evaluation of CHROMagar Orientation for differentiation and presumptive identification of gram-negative bacilli and Enterococcus species. J. Clin. Microbiol. 34: 1788-1793. [Medline]

12. National Mastitis Council 1999. Laboratory Handbook on Bovine Mastitis. Madison, WI: National Mastitis Council.

13. Suojala, L., Simojoki, H., Mustonen, K., Kaartinen, L. and Pyörälä, S. 2010. Efficacy of enrofloxacin in the treatment of naturally occurring acute clinical Escherichia coli mastitis. $J$. Dairy Sci. 93: 1960-1969. [Medline] [CrossRef]

14. Trautmann, M., Zick, R., Rukavina, T., Cross, A. S. and Marre, R. 1998. Antibiotic-induced release of endotoxin: in-vitro comparison of meropenem and other antibiotics. J. Antimicrob. Chemother. 41: 163-169. [Medline] [CrossRef]

15. Wenz, J. R., Garry, F. B. and Barrington, G. M. 2006. Comparison of disease severity scoring systems for dairy cattle with acute coliform mastitis. J. Am. Vet. Med. Assoc. 229: 259-262. [Medline] [CrossRef]

16. Zhao, X. and Lacasse, P. 2008. Mammary tissue damage during bovine mastitis: causes and control. J. Anim. Sci. 86 Suppl: 57-65. [Medline] [CrossRef] 